\title{
Myocardial Bridges and their Relationship to the Anterior Interventricular Branch of the Left Coronary Artery
}

\author{
Vanildo Júnior de Melo Lima, Jennecy Sales Cavalcanti, Tetsuo Tashiro \\ Recife, PE - Brazil
}

\begin{abstract}
Objective - To analyze the relationship between myocardial bridges and the anterior interventricular branch (anterior descending) of the left coronary artery.

Methods - The study was carried out with postmortem material, and methods of dissection and observation were used. We assessed the perimeter of the anterior interventricular branch of the left coronary artery using a pachymeter, calculated its proximal and distal diameters in relation to the myocardial bridge, and also its diameter under the myocardial bridge in 30 hearts. We also observed the position of the myocardial bridge in relation to the origin of the anterior interventricular branch.
\end{abstract}

Results - The diameters of the anterior interventricular branch were as follows: the mean proximal diameter was $2.76 \pm 0.76 \mathrm{~mm}$; the mean diameter under the myocardial bridge was $2.08 \pm 0.54 \mathrm{~mm}$; and the mean distal diameter was $1.98 \pm 0.59 \mathrm{~mm}$. In $33.33 \%$ (10/30) of the cases, the diameter of the anterior interventricular branch under the myocardial bridge was lower than the diameter of the anterior interventricular branch distal to the myocardial bridge. In $3.33 \%(1 / 30)$ of the cases, an atherosclerotic plaque was found in the segment under the myocardial bridge. The myocardial bridge was located in the middle third of the anterior interventricular branch in $86.66 \%$ (26/30) of the cases.

Conclusion - Myocardial bridges are more frequently found in the middle third of the anterior interventricular branch of the left coronary artery. The diameter of the anterior interventricular branch of the left coronary artery under the myocardial bridge may be smaller than after the bridge. Myocardial bridges may not provide protection against the formation of atherosclerotic plaque inside the anterior interventricular branch of the left coronary artery.

Key words: myocardial bridge, coronary arteries, morphometry

Centro de Ciências Biológicas - UFPE

Mailing address: Vanildo Júnior de Melo Lima - Rua Miguel Ângelo, 216 - 50670-320 Recife, PE, Brazil - E-mail: vjr@npd.ufpe.br

English version by Stela Maris C. e Gandour
Coronary arteries and their major branches are usually located subepicardially. Some individuals, however, have regions in which a bunch of cardiac muscle fibers passes over those vessels like a bridge. The following terms have been used to describe this anatomical finding: myocardial bridge, intramural coronary artery, mural coronary artery, and mural coronary ${ }^{1}$.

In vivo studies in human beings began to be performed with angiography from 1960 on, when systolic narrowing of the anterior interventricular branch (anterior descending) of the left coronary artery was observed ${ }^{1}$. Several authors have confirmed that this is the coronary branch most frequently involved with myocardial bridges ${ }^{2-7}$.

The clinical significance of myocardial bridges varies, and most patients are asymptomatic. However, angina, acute myocardial infarction, ventricular fibrillation, myocardial ischemia, cardiac arrhythmias, and sudden death have been reported in association with myocardial bridges ${ }^{8}$. Some authors suggest that myocardial bridges should be added to the list of known causes of sudden death or myocardial infarction in young individuals after strenuous exercise ${ }^{9}$.

The occurrence of atherosclerosis in coronary artery segments under myocardial bridges is controversial. Ishii et al ${ }^{10}$ and Geiringer ${ }^{11}$ reported that mural segments of the anterior interventricular branch of the left coronary artery are rarely affected by atherosclerosis, unlike the epicardial segments, in which atherosclerosis is a common finding. Other authors ${ }^{12}$ concluded that the portions of the coronary arteries involved with bundles of cardiac muscle are not protected from the atherosclerotic process.

Considering the importance of the anterior interventricular branch of the left coronary artery in cardiac irrigation, and the high incidence of myocardial bridges occurring over this vessel, we decided to analyze the relationship between myocardial bridges and the anterior interventricular branch (anterior descending) of the left coronary artery. This subject remains controversial, and we consider it of interest for clinical and interventional cardiology. 


\section{Methods}

We studied 30 human hearts of adult individuals of both sexes with myocardial bridges extending over the anterior interventricular branch of the left coronary artery. The hearts had been fixed in a $10 \%$ formaldehyde solution and belonged to the Department of Anatomy of the Center of Biological Sciences of the Federal University of Pernambuco.

With the aid of a pachymeter (Vernier Calipers, with 0.01 $\mathrm{mm}$ precision), we performed the following measurements: the distance between the origin of the left coronary artery and the origin of its anterior interventricular branch (D1); the distance between the origin of the anterior interventricular branch and the beginning of the myocardial bridge (D2); the distance between the origin of the left coronary artery and the beginning of the myocardial bridge (D3); and the length of the myocardial bridge (C1). We also observed the position of the myocardial bridge over the anterior interventricular branch.

After that, the anterior interventricular branch was transversally sectioned at the 3 following levels: just before its penetration into the myocardium; in the middle point between the vessel's entrance into and emergence from the myocardium, ie, in the middle point of the myocardial bridge; and just after the point where the anterior interventricular branch emerged from the myocardium. Then, the vessel was longitudinally opened and the perimeters at the abovecited levels were measured. This way, the perimeters of the anterior interventricular branch were obtained as follows: just before the myocardial bridge (P1); under the middle point of the bridge (P2); and just after the myocardial bridge (P3). The perimeter obtained in each segment of the anterior interventricular branch was divided by ë (3.14), and the following diameters of the vessel were obtained: just before the myocardial bridge (DV1), under the middle point of the myocardial bridge (DV2), and just after the myocardial bridge (DV3). Data obtained were put in tables and statistically analyzed. Part of this material was photographed with a stereoscopic magnifying glass.

\section{Results}

The results of the measurements of the distances between the origin of the left coronary artery and the origin of the anterior interventricular branch or the beginning of the myocardial bridge, and the length of the myocardial bridge are shown in table I.

Myocardial bridges extended over the proximal third of the anterior interventricular branch in $13.33 \%$ (4/30) of the hearts studied, and over the middle third of that branch in $86.66 \%$ (26/30) of the hearts studied. No myocardial bridge was observed over the distal third of the anterior interventricular branch.

The results of the perimeters measured and the diameters calculated of the anterior interventricular branch in the segments just before the myocardial bridge, under the middle portion of the myocardial bridge, and just after the myocardial bridge are shown in table II.

\begin{tabular}{|c|c|c|c|c|}
\hline \multicolumn{5}{|c|}{$\begin{array}{l}\text { Table I - Results of the measurements of the anterior interventri- } \\
\text { cular branch (AIB) and the myocardial bridges in } 30 \text { hearts (mm) }\end{array}$} \\
\hline & D 1 & D2 & D3 & $\mathrm{C} 1$ \\
\hline Mean & 12.41 & 29.68 & 42.09 & 25.03 \\
\hline SD & 4.78 & 10.94 & 10.55 & 16.47 \\
\hline Max. & 20.43 & 50.73 & 60.98 & 63.12 \\
\hline Min. & 0 & 12.82 & 18.77 & 6.25 \\
\hline \multicolumn{5}{|c|}{$\begin{array}{l}\text { D1 - distance between the origin of the left coronary artery and the origin } \\
\text { of the AIB; D } 2 \text { - distance between the origin of the AIB and the beginning } \\
\text { of the miocardial bridge; D } 3 \text { - distance between the origin of the left } \\
\text { coronary artery and the beginning of the miocardial bridge; C1 - length } \\
\text { of the miocardial bridge; Mean - arithmetic mean; SD - standard deviation; } \\
\text { Max - maximum value; Min - minimum value. }\end{array}$} \\
\hline
\end{tabular}

\begin{tabular}{|c|c|c|c|c|c|c|}
\hline \multicolumn{7}{|c|}{$\begin{array}{l}\text { Table II - Results of the measurements of the perimeters and diameters } \\
\text { of the anterior interventricular branch (AIB) in } 30 \text { hearts (mm) }\end{array}$} \\
\hline & $\mathrm{P} 1$ & $\mathrm{P} 2$ & P3 & DV1 & DV2 & DV3 \\
\hline Mean & 8.65 & 6.53 & 6.21 & 2.76 & 2.08 & 1.98 \\
\hline SD & 2.39 & 1.68 & 1.85 & 0.76 & 0.54 & 0.59 \\
\hline Max & 13.31 & 10.62 & 11.85 & 4.24 & 3.38 & 3.77 \\
\hline Mín & 3.99 & 3.87 & 3.25 & 1.27 & 1.23 & 1.03 \\
\hline \multicolumn{7}{|c|}{$\begin{array}{l}\text { P1 - perimeter of the AIB just before the myocardial bridge; P2 - perimeter } \\
\text { of the AIB under the middle point of the bridge; P3 - perimeter of the AIB } \\
\text { just after the bridge; DV1 - diameter of the vessel just before the bridge; } \\
\text { DV2 - diameter of the vessel under the middle point of the bridge; DV3 } \\
\text { - diameter of the vessel just after the bridge; mean - arithmetic mean; SD } \\
\text { - standard deviation; max - maximum value; min - minimum value. }\end{array}$} \\
\hline
\end{tabular}

The comparison of the diameter of the anterior interventricular branch under the middle point of the myocardial bridge (DV2) with that just before the myocardial bridge (DV1) showed that DV2 was shorter than DV1 in $93.33 \%$ (28/ 30 ) of the hearts studied. However, in $6.66 \%$ (2/30) of the hearts studied, DV2 was longer than DV1. The comparison of DV2 with the diameter of the anterior interventricular branch just after the myocardial bridge (DV3) showed that DV2 was longer than DV3 in 66.66\% (20/30) of the hearts studied and shorter than DV3 in $33.33 \%$ (10/30) of the hearts studied.

In $3(10 \%)$ hearts no atherosclerotic plaque was obser-

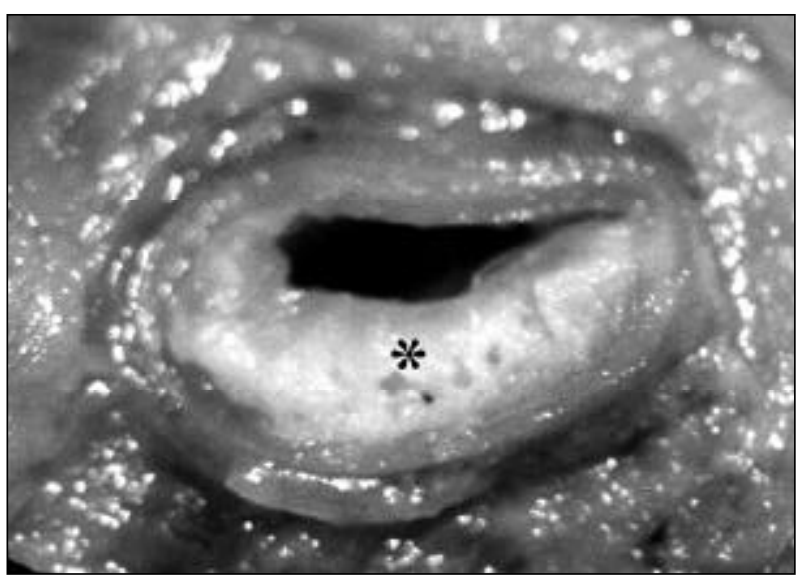

Fig. 1- Photography of a cross section of the segment of the anterior interventricular branch of the left coronary artery under the myocardial bridge with an atherosclerotic plaque inside (*). (Magnification: X 48.5). 
ved in the segment of the anterior interventricular branch just before the myocardial bridge. In 1 (3.33\%) heart, 1 atherosclerotic plaque was observed in the segment of the anterior interventricular branch under the bridge (fig. 1). In 2 $(6.66 \%)$ hearts, atherosclerotic plaques were observed in the segment of the anterior interventricular branch just after the bridge.

\section{Discussion}

Myocardial bridges are cardiac muscle fibers that, from the ventricular myocardium, extend over the coronary arteries. Those bridges may be seen after removing the epicardium and the subepicardial fatty tissue. Ferreira et al ${ }^{13}$ reported 10 cases of myocardial bridges located more deeply, in which a long muscular bundle originated in the right ventricular apical trabeculae, and, after involving the anterior interventricular branch of the left coronary artery, inserted into the interventricular septum.

Some authors ${ }^{2}$ have suggested that myocardial bridges are formed during the embryonic period, at the same time the coronary arteries of the original capillary network are formed. Other authors believe that the myocardial bridges are not an anatomic variation, but a defect in the resorption of the musculature that encircles the arteries that should be epicardial ${ }^{14}$. Peralta et al ${ }^{14}$ stressed that, even though myocardial bridges are congenital, symptoms or problems related to them during childhood are extraordinarily rare, suggesting that extrinsic and chronobiological factors should influence the progression of that entity.

The most frequent position of myocardial bridges in regard to the anterior interventricular branch of the left coronary artery found in our study is similar to that reported by Ferreira et al $^{13}$; that position, however, differs from those reported by Geiringer ${ }^{11}$, Edwards et al $^{12}$, and Polácek and Králové 2 .

In the consulted literature, no data were found about the diameter of the anterior interventricular branch and its relationship to myocardial bridges using the same material conditions and the same method that we used. Kramer et al ${ }^{15}$ studied the diameter of the anterior interventricular branch with angiography and tried to relate the degree of systolic narrowing with the symptoms reported. The degree of systolic constriction reported by them was obtained with an equation that can estimate the degree of constriction of the luminal diameter of the anterior interventricular branch under the myocardial bridge using the relationship between the diameters just before and after the myocardial bridge and the smallest diameter obtained during systole. In our material, we observed that, in $6.66 \%$ (2/30) of the hearts, the diameter of the segment of the anterior interventricular branch under the myocardial bridge was greater than that just before the myocardial bridge, which could mean stenosis proximal to the myocardial bridge. On the other hand, we observed that in $33.33 \%$ (10/30) of the hearts, the diameter of the segment under the bridge was smaller than that just after the bridge, characterizing stenosis of the
Myocardial bridges and the left anterior descending branch

vessel at that level, which would result in hemodynamic alterations ${ }^{16}$. According to Harikrishnan et al ${ }^{17}$, any degree of systolic narrowing of a coronary artery observed in at least 1 angiographic view describes an entity that may be caused by a myocardial bridge.

Vives et $\mathrm{al}^{18}$ reported the case of a patient with electrocardiographic signs of severe ischemia in the area irrigated by the anterior descending artery. The patient evolved with normalization of the electrocardiographic findings, and, on angio-hemodynamic study, the existence of a muscular bridge over the middle third of the anterior descending artery was confirmed with no other associated coronary lesions. According to Peralta et al $^{14}$, myocardial bridges are usually recognized in vivo with an angiographic study when the following findings are observed: a) stretching of the segment of the coronary artery involved; b) uniform reduction in the diameter of the vessel by at least $40 \%$ during systole and recovery of the diameter during diastole (systolic narrowing); c) clear evidence in at least 2 angiographic views, in which the percentage of narrowing is found most in any of the views, and the distal part of the vessel in relation to the bridge is free from compression; d) absence of vasoconstriction induced by drugs or catheters.

Knowing that coronary perfusion is fundamentally diastolic, the isolated finding of myocardial bridges does not explain per se the existence of myocardial ischemia, and other mechanisms, such as tachycardia (diastolic shortening), coronary spasm, and local thrombosis, have been considered to justify it ${ }^{19}$. Recent studies performed with intravascular ultrasonography and coronary Doppler in patients with symptomatic myocardial bridges have shown that vessel compression is not limited to systole, also persisting during diastole, and affects the predominant phase of coronary perfusion ${ }^{20-24}$. A delay in coronary lumen dilation during the beginning of diastole may contribute to the occurrence of coronary ischemia ${ }^{21}$.

According to Roul et $\mathrm{al}^{25}$, the treatment of myocardial bridges should be restricted to symptomatic patients and is primarily based on a pharmacological approach. Beta-blockers are usually the first-line therapy ${ }^{25}$. Another family of drugs used is that of calcium channel blockers ${ }^{25}$. Other therapeutic procedures comprise coronary angioplasty with stent placement ${ }^{8,26,27}$ and surgery ${ }^{25}$. Surgery has been the most frequently used method in patients with symptomatic myocardial bridges, and several techniques, such as coronary artery bypass surgery and supra-arterial muscular resection, have been successfully used. Even though resection of the muscular fibers of the bridge eliminates the subjacent compression, deep incisions in the ventricular wall are frequently necessary with risks of mural aneurysm and scar formation with subsequent recurring vessel compres$\operatorname{sion}^{28}$.

In regard to the occurrence of atherosclerotic plaques in segments of the anterior interventricular branch located under myocardial bridges, Geiringer ${ }^{11}$ reports that mural portions of that vessel are rarely affected by atherosclerosis, unlike epicardial segments, in which atherosclerotic pla- 
ques are commonly found. Other authors state that the atherosclerotic process occurs in mural segments in the same way and with the same frequency as observed in the extramural segn entsoftheartery ${ }^{12}$. Other authors state that coronary artery segments lying under myocardial bridges have a higher tendency to build atherosclerotic plaques than epicardial segments $\mathrm{do}^{2}$. Atherosclerotic coronary stenosis has been angiographically shown in a segment of the anterior interventricular branch under a myocardial bridge ${ }^{28,29}$. Agirbasli et $\mathrm{al}^{9}$ reported the case of a patient with a thrombus inside the middle portion of the anterior interventricular branch of the left coronary artery, covered with an important myocardial bridge (approximate length of $3 \mathrm{~cm}$ ), which was seen on a coronary angiography. A peri-arterial resecti- on surgery was performed which ended the narrowing ${ }^{9}$. Several authors have used intravascular ultrasonography to diagnose an atherosclerotic lesion in segments of the interventricular branch under a myocardial bridge that is not visualized on angiography ${ }^{20-22}$.

Based on our results, we may conclude the following: 1) myocardial bridges are more frequently found in the middle third of the anterior interventricular branch of the left coronary artery; 2) the diameter of the anterior interventricular branch of the left coronary artery under the middle point of myocardial bridges may be shorter than the diameter just after the bridge; 3) myocardial bridges may not provide protection against the formation of atherosclerotic plaques inside the anterior interventricular branch of the left coronary artery.

\section{References}

1. Angelini P, Trivellato M, Donis J, Leachman RD. Myocardial bridge: a review. Prog Cardiovasc Dis 1983; 26: 75-88.

2. Polácek P, Králové H. Relation of myocardial bridges and loops on the coronary arteries to coronary occlusions. Am Heart J 1961; 61: 44-52.

3. Décourt LV, Carvalho VB, Martinez JRM. Ponte miocárdica: uma entidade controvertida. Rev Hosp Clin Fac Med S Paulo 1980; 35: 157-160.

4. Lopes EA, Gutierrez PS. "Pontes miocárdicas" da artéria descendente anterior. Estudo morfológico. Arq Bras Cardiol 1986; 46: 91-3.

5. Bezerra AJC, Didio LJA, Prates JC. Pontes de miocárdio. An Anat Nor 1987; 5 : 59-66.

6. Mandarim-De-Lacerda CA, Souza DSR, Bonfim V. Estudo morfométrico e estatístico da presença de "pontes" miocárdicas sobre o ramo interventricular anterior (descendente anterior) da artéria coronária esquerda em brasileiros. Arq Bras Cardiol 1987; 49: 19-23.

7. Cavalcanti JS, Tavares DS, Queiroz AC, Oliveira LH, Lavor SM. Contribuição ao estudo das pontes miocárdicas em humanos. An Fac Med Univ Fed Pernamb 1994; 39: 18-24.

8. Smith SC, Taber MT, Robiolio PA, Lasala JM. Acute myocardial infarction caused by a myocardial bridge treated with intracoronary stenting. Cathet Cardiovasc Diagn 1997; 42: 209-12.

9. Agirbasli M, Martin GS, Stout JB, Jennings HS, Lea JW, Dixon JH. Myocardial bridge as a cause of thrombus formation and myocardial infarction in a young athlete. Clin Cardiol, 1997; 20: 1032-6.

10. Ishii T, Asuwa N, Masuda S, Ishikawa Y. The effects of a myocardial bridge in coronary atherosclerosis and ischaemia. J Pathol 1998; 185: 4-9.

11. Geiringer E. The mural coronary. Am Heart J 1951; 41: 359-68.

12. Edwards JC, Burnsides C, Swarm RL, Lansing AI. Arteriosclerosis in the intramural and extramural portions of coronary arteries in the human heart. Circulation 1956; 13: 235-41

13. Ferreira Jr AG, Trotter SE, König Jr B, Décourt LV, Fox K, Olsen EGJ. Myocardial bridges: morphological and functional aspects. Br Heart J 1991; 66: 364-7.

14. Peralta MR, Alfaro JK, Gómez A, et al. Puentes miocárdicas. Papel de la microcirculación, reserva coronaria y daño endotelial sistólico. Arch Inst Cardiol Méx 1998; 68: 506-14

15. Kramer JR, Kitazume H, Proudfit WL, Sones FM. Clinical significance of isolated coronary bridges: benign and frequent condition involving the left anterior descending artery. Am Heart J 1982; 103: 283-8.

16. Klues HG, Schwarz ER, Dahl JV, et al. Disturbed intracoronary hemodynamics in myocardial bridging. Early normalization by intracoronary stent placement. Circulation 1997; 96: 2905-13.

17. Harikrishnan S, Sunder KS, Tharakan J, Titus T, Bhat A, Sivasankaran FB. Clinical and angiographic profile and follow-up of myocardial bridges: a study of 21 cases. Indian Heart J 1999; 51: 503-7.

18. Vives MAA, Dolz LVM, Bonet LA, Lalaguna LA, Morro FT, Pérez MP. Puente miocárdico como causa de isquemia aguda. Descripción del caso y revisión de la bibliografia. Rev Esp Cardiol 1999; 52: 441-4.

19. Laurent $\mathrm{G}$, Cottin $\mathrm{Y}$, André $\mathrm{F}$, et al. Ponts myocardiques symptomatiques. À propos de 6 cas. Arch Mal Cœur 1996; 89: 883-7.

20. Winter RJ, Kok WEM, Piek JJ. Coronary atherosclerosis within a myocardial bridge, not a benign condition. Heart 1998; 80: 91-3.

21. Hongo Y, Tada H, Ito K, Yasumura Y, Miyatake K, Yamagishi M. Augmentation of vessel squeezing at coronary-myocardial bridge by nitroglycerin: study by quantitative coronary angiography and intravascular ultrasound. Am Heart J 1999; 138: 345-50.

22. Jain SP, White CJ, Ventura HO. De novo appearence of a myocardial bridge in heart transplant: assessment by intravascular ultrasonography, doppler and angioscopy. Am Heart J 1993; 126: 453-6.

23. Schwarz ER, Klues HG, vom Dahl J, Klein I, Krebs W, Hanrath P. Functional, angiographic and intracoronary doppler flow characteristics in syntomatic patients with myocardial bridging: effect of short-term intravenous beta-blocker medication. J Am Coll Cardiol 1996; 27: 1637-45.

24. Ge J, Jeremias A, Rupp M, et al. New signs characteristic of myocardial bridging demonstrated by intracoronary ultrasound and doppler. Eur Heart J 1999; 20: 1707-16.

25. Roul G, Sens P, Germain P, Bareiss P. Myocardial bridging as a cause of acute transient left heart dysfunction. Chest 1999; 116: 574-80.

26. Agirbasli M, Hillegass WB, Chapman GD, Brott BC. Stent procedure complicated by thrombus formation distal to the lesion winthin a muscle bridge. Cathet Cardiovasc Diagn 1998; 43: 73-6.

27. Prendergast BD, Kerr F, Starkey IR. Normalisation of abnormal coronary fractional flow reserve associated with myocardial bridging using an intracoronary stent. Heart 2000; 83:705-7.

28. Parashara DK, Ledley GS, Kotler MN, Yazdanfar S. The combined presence of myocardial bridging and fixed coronary artery stenosis. Am Heart J 1993; 125 : 1170-2.

29. Ramos SG, Montenegro AP, Felix PR, Kazava DK, Rossi MA. Occlusive thrombosis in myocardial bridging. Am Heart J 1993; 125: 1771-3. 